5. Tang M, Hou J, Wu D, Han XY, Zeng MS, Yao XZ. Glomustumor in the stomach: Computed tomography and endoscopic ultrasound findings. World $J$ Gastroenterol. 2013;19(8):1327-1329.

6. Miettinen M, Paal E, Lasota J, et al. Gastrointestinal glomustumors. Am J Surg Pathol. 2002;26:301-311.

7. Vassiliou I, Tympa A, Theodosopoulos T, Dafnios N, Fragulidis G, Koureas A, Kairi E. Gastric glomus tumor: A case report. World J Surg Oncol. 2010,8:19.

\section{Stapler hepatectomy in giant cavernous hemangioma of liver}

Cavernous hemangiomas are the most common benign tumor of the liver. On autopsy, their incidence ranges from $5 \%$ to $20 \%{ }^{1,2}$

\section{Case Report}

A middle aged married female presented with complaints of mass per abdomen since 3 months and pain in the upper abdomen since 1 month. She had no history of jaundice or oral contraceptive use. On examination, a single swelling measuring $15 \times 10 \mathrm{~cm}$ was found in the left hypochondrium and epigastrium crossing the mid line medially, up to the umbilicus inferiorly. Contrast enhanced computed tomography (CECT) revealed a 13x10x15 cms well defined heterogenous soft tissue density in segment II,III and IV with peripheral discontinuous enhancement in arterial phase, while in venous and delayed phase centripetal filling with non-enhancing areas were seen (Figure 1). The impression obtained on the CECT scan was of an atypical hemangioma. All the routine blood investigations were within normal limits except for anaemia. She was planned for left hepatectomy. Her abdomen was opened through a Mercedes benz incision. Introperatively, we found a $15 \times 10 \times 10 \mathrm{cms}$ mass in the left lobe to the left of the falciform ligament. Compensatory hypertrophy of the right and caudate lobes was also observed. There was no evidence of portal hypertension. GIA $45 \mathrm{~mm}$ stapler was used for parenchymatous transection and left hepatic vein
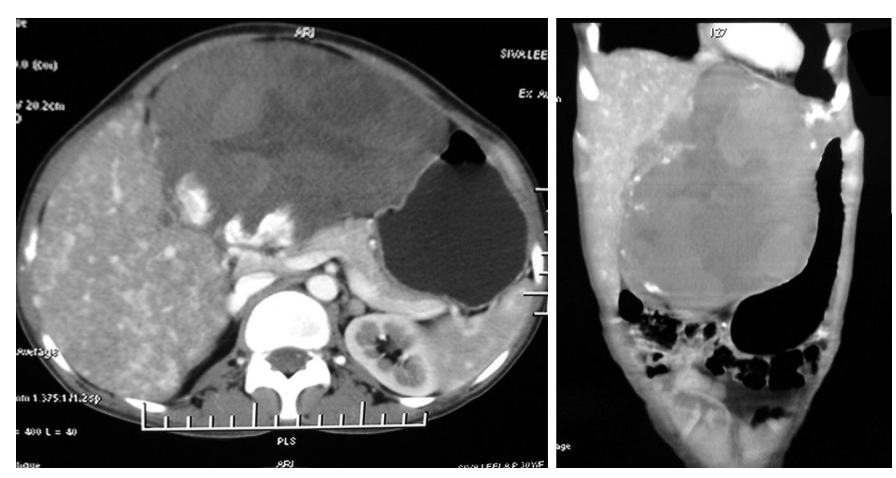

Figure 1: Contrast enhanced computed tomography (CECT) revealed a $13 \times 10 \times 15 \mathrm{cms}$ well defined heterogenous soft tissue density in segment II,III and IV with peripheral discontinuous enhancement in arterial phase, while in venous and delayed phase centripetal filling with nonenhancing areas were seen.
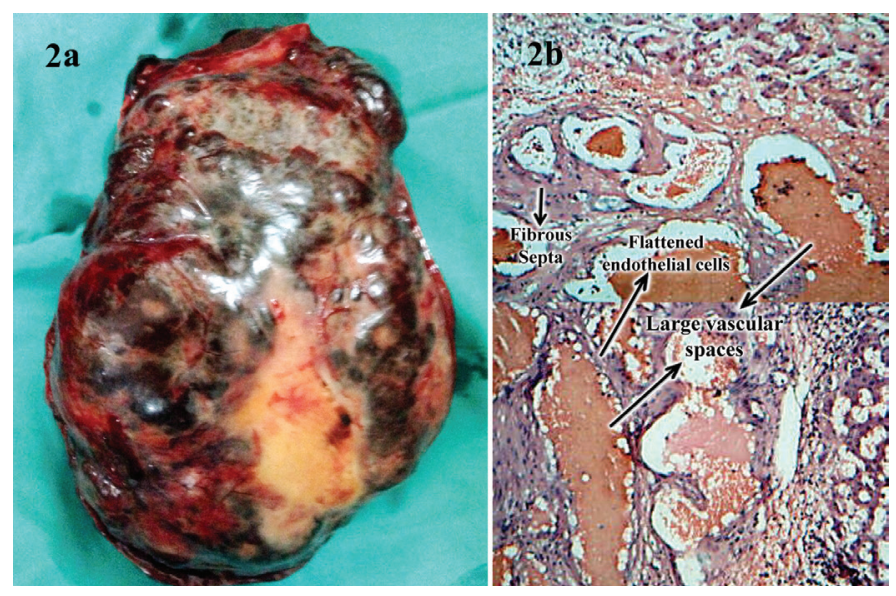

Figure 2: (a) Specimen photograph. (b) Histopathology - Dilated variably sized vascular spaces, predominantly large lined by flattened endothelial cells with intervening fibrous connective tissue septa, extending into adjoining liver parenchyma with areas of infarction and necrosis.

was ligated with prolene 3-0 suture. Histopathological examination revealed a cavernous hemangioma (Figure 2,2a).

\section{Discussion}

Gianthemangiomas were first defined by Adam et al in 1970 as cavernous hemangiomas larger than $4 \mathrm{~cm}$ 
in diameter. ${ }^{3}$ In $85 \%$ of cases, hemangiomas are clinically asymptomatic and are incidentally detected in imaging. Diffuse hepatic hemangiomatosis usually occurs in neonates and is associated with Rendu-Osler-Weber disease or skeletal hemangiomatosis. ${ }^{4,5}$ Surgical resection is the most commonly used treatment modality. A stable hemangioma has a rupture rate of $1 \%$ to $4 \%$ and after rupture, a fatality rate of $60 \%$ to $75 \%$. The natural history is variable, and they can regress spontanteously, undergo thrombosis, scarring (called as sclerosed hemangioma) or calcifiation. Close follow-up without intervention is the best way of management of asymptomatic cases. The available treatment options include radiotherapy, interferon therapy, transcatheter arterial embolization (TAE), radiofrequency ablation, arterial ligation, corticosteroid therapy and liver transplantation. Spontaneous or traumatic rupture, intra tumoral hemorrhage, consumption coagulopathy (KasabachMerritt Syndrome) and a rapid growth rate are absolute surgical indications. Surgery remains the only consistently effective curative treatment for giant haemangiomas. An everlasting debate exists between enucleation and hepatic resection, both having equal efficacy and a decision is usually made on the size of tumor. However, Kayanet $\mathrm{al}^{6}$ reported that the combination of preoperative percutaneous trans-catheterarterial embolization and surgery is a safe procedure that eliminates the risk of intraoperative bleeding. In unresectable lesions, when there is multiple bilobar involvement, and in symptomatic cases with hepatic hilum involvement, liver transplantation is the most appropriate approach. Indications for liver transplantation in cases of hepatic hemangioma include acute and chronic hepatic failure, such as occurrence of Kasabach-Merritt syndrome, giant hepatic hemangioma affecting the normal liver tissue eventually causing liver dysfunction, and a life-threatening giant hepatic hemangioma that cannot be resected. ${ }^{7}$ Stapler Hepatectomy mode of transection is fast with less bleeding from parenchyma and easy for left lobe resection.

\section{MANISEGARAN} ANUROOP THOTA

NRI Academy of Medical Sciences, Andhra Pradesh.

Correspondence: Anuroop Thota Email:anuroopt@gmail.com

\section{References}

1. Weimann A, Ringe B, Klempnauer J et al. Benign liver tumors: differential diagnosis and indications for surgery. World J Surg. 1997;21:983-990; discussion 990-991.

2. Ishak KG, Rabin L. Benign tumors of the liver. Med Clin North Am. 1975;59:995-1013.

3. Adam YG, Huvos AG, Fortner JG. Giant hemangiomas of the liver. Ann Surg. 1970;172:239-245.

4. Gutierrez RM, Spjut HJ. Skeletal angiomatosis: report of three cases and review of the literature. Clin Orthop Relat Res. 1972;85:82-97.

5. Haitjema T, Westermann CJ, Overtoom TT et al. Hereditary hemorrhagic telangiectasia (Osler-Weber-Rendu disease): new insights in pathogenesis, complications, and treatment. Arch Intern Med. 1996;156:714-719.

6. Kayan M, Cetin M, Aktaş AR et al. Pre-operative arterial embolization of symptomatic giant hemangioma of the liver. Prague Med Rep. 2012;113:166-171.

7. Lin Zhong, Tong-Yi Men, Gao-di Yang et al. Case report: living donor liver transplantation forgiant hepatic hemangioma using a right lobegraft without the middle hepatic vein. World Journal of Surgical Oncology. 2014,12:83. 